\title{
Sala de aula na universidade: espaço de relações interpessoais e participação acadêmica
}

\author{
The college classroom: a place for interpersonal \\ relationships and academic participation
}

\author{
Isabel Cristina Dib BARIANI' \\ Renatha PAVANI ${ }^{2}$
}

\begin{abstract}
Resumo
Entendendo ser fundamental a incrementação de pesquisas sobre as relações interpessoais no âmbito da educação universitária, objetivou-se descrever e analisar as relações professor-aluno e aluno-aluno e os motivos que levam os estudantes a assumir diferentes atitudes em sala de aula, relativas a interesse e participação, segundo os próprios discentes e seus professores. As informações foram coletadas com 21 professores e 90 alunos de um Curso de Psicologia, por meio de questionários abertos. Os dados foram submetidos à análise categorial e, posteriormente, à análise quantitativa. Foram formuladas as seguintes categorias: Estrutural, Interacional, Pedagógica, Comportamental e Comprometimento. Os aspectos associados às relações interpessoais em sala de aula são de cunho positivo para as aulas práticas e negativo para as teóricas. Como principal motivo para o interesse e a participação em sala de aula, são apontados aspectos relativos à categoria Pedagógica, em especial à sub-categoria Procedimentos de Aula.
\end{abstract}

Unitermos: Educação superior. Formação profissional. Relação aluno-aluno. Relação professor-aluno.

\begin{abstract}
As the increase of research into interpersonal relationships in the sphere of university education is regarded as fundamental, this study has aimed to describe and analyze teacher-pupil and pupil-pupil relationships and the reasons why students behave in different ways in the classroom, in terms of their interest and participation, according to the pupils themselves and their teachers. The information was collected from 21 teachers and 90 students of a Psychology Course by way of open questionnaires. The data was submitted to categoric analysis and, subsequently, to quantitative analysis. The following categories were formulated: structural, interactional, pedagogic, behavioral and commitment. The aspects associated with interpersonal relationships in the classroom are seen to be positive for the practical classes and negative for the theoretical ones. Those aspects related to the Pedagogic category are shown to be the main reason for interestand participation in the classroom, especially those relating to the Classroom Procedures sub-category.
\end{abstract}

Uniterms: Education degrees. Professional development. Student-student relationship. Teacher student relationship.

1 Pontifícia Universidade Católica de Campinas, Centro de Ciências da Vida, Faculdade de Psicologia. Av. John Boyd Dunlop, s/n., Jd. Ipaussurama, 13060-904, Campinas, SP, Brasil. Correspondência para/Correspondence to: I.C.D. BARIANI. E-mail: <crisdib@sigmanet.com.br>.

2 Universidade Estadual de Campinas. Campinas, SP, Brasil.

Agradecimentos: Ao apoio institucional proveniente da PUC-Campinas, em especial, ao órgão financiador FAPIC. 
A importância das relações interpessoais do professor com o aluno para o processo ensino-aprendizagem vem sendo apontada em diversos estudos, tal como o fazem Silva e Aranha (2005). Entretanto, trata-se de pesquisas que focam especificamente a influência que o professor exerce sobre a aprendizagem de seus alunos, ignorando o quanto estes últimos interferem na postura pedagógica adotada pelo primeiro.

Assim, são encontradas diversas pesquisas que apontam coerentemente quais características um professor deve ter para promover uma melhor aprendizagem de seus alunos, como a de Oliveira e Wechsler (2002), mas poucas que revelam como a atuação do professor pode ser influenciada pela classe de alunos.

Esta produção científica desigual pode ser justificada, de acordo com Silva e Aranha (2005), pelo fato de que, durante muito tempo, acreditou-se que o professor era o único responsável pelos resultados alcançados no processo ensino-aprendizagem. Assim, apesar de não ser tão recente a constatação de que o aluno exerce influência sobre o professor - ou seja, que a relação entre eles é marcada pela bi-direcionalidade -, Zuin (2003) destaca que as pesquisas continuam voltando-se unicamente à influência do professor sobre o aluno, presas à concepção de que o primeiro, infalível, não estaria vulnerável à postura adotada por esse último.

Analogamente às poucas investigações a respeito da influência exercida pelo aluno sobre o professor, são escassas as que verificam como as interações estabelecidas entre os alunos influenciam a construção do conhecimento dos mesmos. Coll e Colomina (1996) acreditam que o desinteresse dos estudiosos por este aspecto das relações interpessoais estabelecidas em sala de aula deva-se à importância tradicionalmente atribuída à relação professor-aluno como fator determinante da aprendizagem escolar.

Entretanto, os poucos pesquisadores que voltam o olhar para as relações que os alunos estabelecem entre si afirmam o quanto elas se fazem influentes no momento da aprendizagem. Dentre eles, pode-se destacar Kienen e Botomé (2003), que aplicaram um questionário em 23 alunos de um curso de Psicologia, com o objetivo de caracterizar as relações existentes entre o controle institucional para que o aluno tenha um bom desempenho e o seu estado de saúde. A partir da realização de sua pesquisa, os autores constataram que os participantes se incomodavam com a postura individualista de seus colegas, apontando que, ao invés de cooperarem entre si, formando uma verdadeira parceria, assumiam posturas de falta de apoio e até mesmo de rivalidade.

A pesquisa realizada por Kienen e Botomé (2003) deve ser destacada não apenas por ser uma das poucas que discutem as relações estabelecidas entre os alunos, mas, também, por ter sido realizada em um contexto universitário. A maioria das investigações sobre as relações humanas estabelecidas em sala de aula não apenas focaliza unicamente a interação estabelecida entre professor e aluno (e, dentro desta, a influência do professor sobre o aluno), mas voltam-se ao Ensino Fundamental e Médio, ignorando, tal como aponta Bariani (1991), a importância das relações interpessoais estabelecidas no Ensino Superior.

Talvez os estudiosos estejam se voltando ao Ensino Fundamental e Médio por conceberem que, nesta etapa escolar, os alunos dependem maciçamente da figura do professor, não apenas no que diz respeito à aquisição de conhecimentos teóricos, mas, também, como afirmam Silva e Aranha (2005), no que tange à sua formação enquanto pessoas que pertencem a uma sociedade.

Entretanto, não estão os universitários também em formação? Será que eles, assim como os alunos dos níveis de ensino anteriores, não demandam igualmente a presença de um docente que Ihes forneça mais que informações?

Entendendo ser fundamental a incrementação de pesquisas sobre este assunto, que possam fornecer elementos para auxiliar e, inclusive, direcionar e melhorar a formação e atuação profissional, este estudo objetivou: 1) descrever e analisar as relações professor-aluno e aluno-aluno, segundo docentes e discentes universitários; 2) identificar, descrever e analisar os motivos que levam os estudantes a assumir diferentes atitudes em sala de aula (de participação produtiva, crítica e criativa, ou de desinteresse e apatia), segundo os próprios discentes e seus professores.

\section{Método}

Os dados foram coletados por meio de um questionário com docentes e discentes de 1a a 4a séries 
de um Curso de Psicologia, sendo que todos os sujeitos assinaram o termo de consentimento livre e esclarecido, conforme orientação da Resolução no 196/96 do Ministério da Saúde (1996), sobre pesquisa envolvendo seres humanos.

Embora a totalidade dos docentes tenha sido solicitada a participar, 21 professores (44\% do total) responderam a esta pesquisa, sendo três do gênero masculino e 18 do feminino. $O$ tempo de experiência docente variou de 3 a 32 anos, com tempo médio de 19,2 anos. Quanto à titulação, nove eram doutores, cinco mestres, dois com especialização, um cursava doutorado, outro mestrado e três não especificaram. Os questionários foram entregues aos docentes por meio dos escaninhos da sala dos professores, solicitando-se que, quando estivessem respondidos, fossem colocados no envelope que se encontrava no escaninho da professora responsável por este estudo.

Após a autorização dos professores responsáveis pelas aulas, os discentes foram contatados em suas salas e todos os presentes foram convidados a responder ao questionário. Após a aplicação, a amostra discente foi selecionada aleatoriamente, ficando composta por 10 alunos de cada uma, das três turmas de $1^{\text {a }}$ série (duas diurnas e uma noturna) e das duas turmas de $2^{a}$ a $4^{a}$ séries (todas funcionando em período integral), totalizando 90 estudantes, 81 do gênero feminino e nove do masculino, com idades variando entre 18 e 43 anos, com média de 21 anos.

O questionário utilizado foi planejado com duas partes, uma para obtenção de dados pessoais e outra contendo as perguntas abertas destinadas à consecução dos objetivos propostos, que são apresentadas a seguir.

1) Levando em consideração o seu cotidiano em sala de aula, descreva:

1.1) As relações dos alunos da sala com os professores, em aulas teóricas (classe completa) e práticas (grupos pequenos);

1.2) As relações dos alunos da sala entre si, em aulas teóricas (classe completa) e práticas (grupos pequenos)

2) Aponte os motivos que levam os alunos a:

2.1) Se interessarem ou não pelas aulas teóricas (classe completa) e práticas (grupos pequenos);
2.2) Participarem ou não das aulas teóricas (classe completa) e práticas (grupos pequenos).

É importante destacar que, previamente à aplicação definitiva, a segunda parte do instrumento foi submetida a duas testagens, buscando garantir a sua inteligibilidade e adequação.

\section{Resultados e Discussão}

Inicialmente, as informações coletadas foram submetidas à análise categorial. Assim, as informações fornecidas por docentes e discentes foram tratadas e analisadas a partir das categorias e sub-categorias apresentadas a seguir, sendo tratadas distintamente as respostas com sentido positivo (+) e negativo (-). Deve ser esclarecido que, embora tenha sido solicitado que os informantes respondessem considerando as aulas teóricas $(T)$ e as práticas $(P)$, alguns não especificaram, e suas respostas foram tratadas de um modo geral (G).

A seguir, são descritas as categorias de análise.

A) Estrutural - refere-se aos aspectos relativos à estrutura curricular do curso, especialmente, àqueles voltados à organização da vida escolar do aluno, como: A1) Disciplinas; A2) Modulação; e A3) Materiais.

B) Interacional - tem como foco as interações humanas em sala de aula, como: B1) Relação Professor-Aluno; B2) Relação Aluno-Aluno na Turma; e B3) Relação Aluno-Aluno nos Sub-grupos.

C) Pedagógica - abrange aspectos relativos às características dos procedimentos e atividades desenvolvidas no espaço da sala de aula, como: C1) Conteúdos; (2) Procedimentos de Aula; (3) Trabalho Docente/Comprometimento; e (4) Avaliação do Desempenho Acadêmico.

D) Comportamental - o comportamento do sujeito é o foco da situação, seja o comportamento individual ou o comportamento característico de grupos. Assim, foram consideradas sub-categorias: D1) Grupal; D2) Individual do Professor; e D3) Individual do Aluno.

E) Comprometimento - refere-se às preocupações com a graduação, como: E1) Desempenho Acadêmico; e E2) Formação Profissional do Aluno.

Os resultados foram descritos segundo a seguinte organização: 1) As relações dos alunos da sala entre 
si; 2) As relações dos alunos da sala com os professores; 3) Motivos que levam os alunos a se interessar ou não pelas aulas; e 4) Motivos que levam os alunos a participar ou não das aulas.

\section{As relações dos alunos da sala entre si}

O primeiro dado que chama a atenção relaciona-se à divergência com que os alunos parecem perceber as aulas teóricas e práticas. Em relação às primeiras, as respostas dos participantes foram categorizadas, em sua maioria, com sentido negativo, uma vez que apenas 26 (21\%) eram de cunho positivo, em contraposição a 96 (79\%), que possuíam um caráter negativo. Por outro lado, ao se referirem às aulas práticas, 114 (96\%) tinham sentido positivo e apenas cinco (4\%) negativo (Tabela 1).

Pode-se observar mais detalhadamente esta gritante divergência na categoria Interacional, a mais citada dentre todas ( $n=159)$. Enquanto, para as aulas teóricas, houve predominantemente menção ao relacionamento em sub-grupos (as conhecidas"panelinhas"), com sentido negativo ( $n=31)$, nas aulas práticas, houve uma concentração de respostas classificadas como positivas, no que se refere à relação entre os alunos da turma como um todo ( $n=52)$. Assim, a relação dos alunos da sala entre si, nas aulas teóricas, parece ser marcada pela formação de sub-grupos. Um aluno deixa claro porque tais sub-grupos são vistos de maneira tão depreciativa, ao apontar: "... existem grupos pré-definidos, os grupos não se misturam e sentam sempre no mesmo lugar".

Analogamente, as aulas práticas acabam perdendo esta característica da formação de sub-grupos, conseguindo promover um relacionamento em que os alunos interagem entre si, independentemente dos sub-grupos a que pertencem. Isto fica claro na seguinte fala de um aluno: "... a diferença é que nas aulas práticas os grupinhos se separam, havendo menos conversa e, sendo assim, é mais fácil prestar atenção, além de possibilitar a criação de grupos diferentes, o relacionar com outras pessoas".

Esta diferente configuração grupal que é vislumbrada nas aulas práticas parece estar relacionada ao menor número de alunos que nela estão presentes, em relação às aulas teóricas, nas quais a classe inteira de alunos faz-se presente. É possível observar esta lógica na Tabela 1, onde a sub-categoria Modulação (compreendida como o número de alunos em sala de aula) é apontada, em unanimidade, com sentido positivo ( $n=29)$ nas aulas práticas e, nas aulas teóricas, assim o é em termos negativos $(n=9)$.

Pode ser observado na Tabela 1 que, assim como os estudantes, os professores deram ênfase aos aspectos negativos (90\%) nas aulas teóricas, em contraposição aos aspectos positivos (10\%), bem como, nas aulas práticas, enfatizaram os positivos (94\%), em relação aos negativos (6\%).

Tabela 1. Freqüência das categorias e sub-categorias apontadas pelos alunos de 1a a $4^{a}$ séries e pelos professores sobre a relação aluno-aluno, em aulas teóricas (T), práticas (P) e nas aulas de um modo geral (G), com sentido positivo (+) e negativo (-).

\begin{tabular}{|c|c|c|c|c|c|c|c|c|c|c|c|c|c|}
\hline \multirow{3}{*}{ Categorias } & \multirow{3}{*}{ Sub-categorias } & \multicolumn{6}{|c|}{ Alunos de $1^{\text {a a }} 4^{\text {a }}$ séries } & \multicolumn{6}{|c|}{ Professores } \\
\hline & & \multicolumn{2}{|c|}{$\mathrm{T}$} & \multicolumn{2}{|c|}{$P$} & \multicolumn{2}{|c|}{$G$} & \multicolumn{2}{|c|}{$\mathrm{T}$} & \multicolumn{2}{|c|}{$P$} & \multicolumn{2}{|c|}{$G$} \\
\hline & & + & - & + & - & + & - & + & - & + & - & + & - \\
\hline \multirow[t]{2}{*}{ A) Estrutural } & Disciplina & 0 & 0 & 0 & 0 & 0 & 0 & 0 & 3 & 1 & 0 & 0 & 0 \\
\hline & Modulação & 0 & 9 & 29 & 0 & 0 & 0 & 0 & 0 & 2 & 0 & 0 & 0 \\
\hline \multirow[t]{3}{*}{ B) Interacional } & Relação professor-aluno & 0 & 0 & 0 & 0 & 0 & 0 & 0 & 1 & 2 & 0 & 1 & 0 \\
\hline & Relação aluno-aluno na turma & 23 & 21 & 52 & 1 & 16 & 3 & 1 & 9 & 12 & 0 & 4 & 1 \\
\hline & Relação aluno-aluno no subgrupo & 2 & 31 & 1 & 2 & 1 & 6 & 0 & 5 & 2 & 1 & 0 & 2 \\
\hline \multirow[t]{2}{*}{ C) Pedagógica } & Conteúdos & 0 & 1 & 4 & 0 & 0 & 0 & 1 & 0 & 1 & 0 & 0 & 0 \\
\hline & Procedimentos de aula & 1 & 2 & 23 & 0 & 0 & 0 & 0 & 1 & 5 & 0 & 0 & 0 \\
\hline \multirow[t]{3}{*}{ D) Comportamental } & Grupal & 0 & 21 & 5 & 1 & 1 & 1 & 1 & 6 & 3 & 0 & 0 & 2 \\
\hline & Individual do professor & 0 & 0 & 0 & 0 & 0 & 0 & 0 & 0 & 2 & 0 & 0 & 0 \\
\hline & Individual do aluno & 0 & 11 & 0 & 1 & 0 & 4 & 0 & 1 & 1 & 1 & 0 & 1 \\
\hline E) Comprometimento & Formação profissional do aluno & 0 & 0 & 0 & 0 & 0 & 0 & 0 & 1 & 0 & 0 & 0 & 0 \\
\hline Total & & 26 & 96 & 114 & 5 & 18 & 14 & 3 & 27 & 31 & 2 & 5 & 6 \\
\hline
\end{tabular}


Há, ainda, outra semelhança percebida entre as respostas dos dois grupos de informantes: assim como os alunos, que sequer mencionaram as sub-categorias Relação Professor-Aluno e Comportamento do Professor, os docentes pouco mencionaram estas sub-categorias. Parece, pela pouca menção à figura do docente, dentro da temática "relações dos alunos da sala entre si", que tanto alunos quanto professores percebem o papel do docente de maneira desvinculada das relações que os alunos estabelecem entre si, como se houvessem dois tipos de interações (a relação professor-aluno e a relação aluno-aluno) que, ao invés de se influenciarem mutuamente, ocorressem de maneiras totalmente distintas.

Sabe-se, entretanto, conforme destacam Kienen e Botomé (2003), que o professor pode influenciar a relação estabelecida entre os alunos. Assim como ele pode criar um ambiente menos individualista ao propor a realização de trabalhos em grupo, pode, igualmente, promover um campo competitivo ao comparar os alunos.

\section{As relações dos alunos da sala com os professores}

Na Tabela 2, visualizam-se as respostas dos alunos e dos docentes sobre as relações dos estudantes com os professores.
A partir da análise dos dados, observa-se que, para os alunos, as aulas teóricas concentram mais respostas negativas que positivas (respectivamente, 75\% e 25\%), ao contrário das práticas, que foram mencionadas de maneira predominantemente positiva (90\%).

Ainda na Tabela 2, os dados referentes às respostas dos docentes sobre as relações dos alunos com os professores indicam que a diferença entre aulas teóricas e práticas é ainda mais acentuada, uma vez que as primeiras concentraram mais respostas negativas que positivas (91\% e 9\%), e as práticas tiveram respostas quase que unicamente positivas (97\% e 3\%).

Percebe-se que, assim como quando questionados a respeito das relações dos alunos entre si, os dois grupos de participantes apresentaram respostas predominantemente positivas, no que tange às aulas práticas, e negativas, no que se refere às teóricas, o mesmo pôde ser observado ao serem indagados sobre as relações dos alunos com os professores.

Esta preferência dos dois grupos de participantes pelas aulas práticas, em detrimento das aulas teóricas, pode estar relacionada ao fato de que, em classes menores, torna-se possível para o professor atentar para a singularidade de cada um de seus alunos, aspecto destacado por Moraes e Bernardino (2004), o que é mais difícil de ocorrer em uma sala de aula composta por muitos alunos, como é o caso das aulas teóricas.

Tabela 2. Freqüência das categorias e sub-categorias apontadas pelos alunos de $1^{\text {a }}$ a $4^{a}$ séries e pelos professores sobre a relação aluno-professor, em aulas teóricas (T), práticas (P) e nas aulas de um modo geral (G), com sentido positivo (+) e negativo (-).

\begin{tabular}{|c|c|c|c|c|c|c|c|c|c|c|c|c|c|}
\hline \multirow{3}{*}{ Categorias } & \multirow{3}{*}{ Sub-categorias } & \multicolumn{6}{|c|}{ Alunos de $1^{\text {a a }} 4^{\text {a }}$ séries } & \multicolumn{6}{|c|}{ Professores } \\
\hline & & \multicolumn{2}{|c|}{$\mathrm{T}$} & \multicolumn{2}{|c|}{$P$} & \multicolumn{2}{|c|}{ G } & \multicolumn{2}{|c|}{$T$} & \multicolumn{2}{|c|}{ P } & \multicolumn{2}{|c|}{ G } \\
\hline & & + & - & + & - & + & - & + & - & + & - & + & - \\
\hline A) Estrutural & Modulação & 0 & 5 & 21 & 1 & 0 & 0 & 0 & 3 & 5 & 0 & 0 & 0 \\
\hline \multirow[t]{3}{*}{ B) Interacional } & Relação professor-aluno & 8 & 16 & 43 & 3 & 16 & 8 & 0 & 5 & 11 & 0 & 5 & 1 \\
\hline & Relação aluno-aluno na turma & 1 & 1 & 1 & 0 & 1 & 0 & 0 & 1 & 0 & 0 & 0 & 0 \\
\hline & Relação aluno-aluno no sub-grupo & 0 & 1 & 0 & 0 & 0 & 1 & 0 & 0 & 0 & 0 & 0 & 0 \\
\hline \multirow[t]{4}{*}{ C) Pedagógica } & Conteúdos & 0 & 2 & 2 & 1 & 0 & 2 & 1 & 1 & 1 & 0 & 0 & 0 \\
\hline & Procedimentos de aula & 2 & 6 & 23 & 2 & 2 & 5 & 0 & 1 & 4 & 0 & 0 & 1 \\
\hline & Trabalho docente & 1 & 1 & 2 & 0 & 0 & 1 & 0 & 1 & 1 & 0 & 0 & 0 \\
\hline & Avaliação do desempenho acadêmico & 0 & 0 & 0 & 0 & 0 & 0 & 0 & 1 & 1 & 0 & 0 & 0 \\
\hline \multirow[t]{3}{*}{ D) Comportamental } & Grupal & 1 & 5 & 2 & 1 & 0 & 7 & 0 & 1 & 3 & 1 & 0 & 3 \\
\hline & Individual do professor & 2 & 5 & 3 & 1 & 1 & 6 & 0 & 1 & 0 & 0 & 0 & 1 \\
\hline & Individual do aluno & 0 & 3 & 0 & 0 & 1 & 4 & 1 & 4 & 0 & 0 & 0 & 1 \\
\hline \multirow[t]{2}{*}{ E) Comprometimento } & Desempenho acadêmico & 0 & 0 & 0 & 0 & 0 & 0 & 0 & 1 & 2 & 0 & 0 & 0 \\
\hline & Formação profissional do aluno & 0 & 0 & 0 & 0 & 0 & 0 & 0 & 0 & 0 & 0 & 0 & 1 \\
\hline Total & & 15 & 45 & 97 & 9 & 21 & 34 & 2 & 20 & 28 & 1 & 5 & 8 \\
\hline
\end{tabular}


Esta sintonia nas respostas dos informantes, no que diz respeito à maneira como vêem as relações dos alunos entre si e dos alunos com os professores, não causa estranheza, uma vez que, conforme dito previamente, era de se esperar que estas duas formas de relacionamento interpessoal estivessem entrelaçadas uma à outra, a despeito de, neste estudo, estarem sendo abordadas distintamente.

É interessante refletir que, apesar de as respostas sobre as relações dos alunos entre si e dos alunos com os professores estarem afinadas, ainda assim ambos os grupos de participantes demonstraram não perceber esta sintonia. Isto apareceu não apenas na Tabela 1, com a já discutida ausência da menção, pelos estudantes, à categoria Relação Professor-Aluno, quando indagados sobre as relações dos alunos entre si, mas também na pouca menção à categoria Relação Aluno-Aluno na pergunta sobre as relações dos alunos com os professores, conforme mostrado na Tabela 2.

Esta falta de compreensão, por parte dos docentes e discentes, do quanto as relações dos alunos entre si e as relações dos alunos com os professores estão atreladas, torna-se mais preocupante no que concerne especificamente ao primeiro grupo, haja vista que, segundo Moraes e Bernardino (2003), o professor é dotado de uma certa autoridade - mesmo que ele não seja autoritário em seu estilo pedagógico - e acaba sendo o maior responsável pelas relações que são estabelecidas em sala de aula, ainda que não tenha consciência disso. Assim, conforme aponta Zuin (2003), quando um aluno é elogiado ou humilhado por um professor, diante de todos os seus colegas, não será apenas a relação professor-aluno que estará em pauta, mas, também, as relações dos demais alunos da sala com este estudante em questão.

\section{Motivos que levam os alunos a se interessar ou não pelas aulas}

Na Tabela 3, observa-se as categorias nas quais as respostas dos discentes e dos docentes sobre os motivos que os levam a se interessar pelas aulas mais se concentraram.

A categoria que concentrou notadamente o maior número de respostas dos discentes foi a Pedagógica ( $n=125$ ), dentro da qual a sub-categoria Procedimento de Aula destacou-se tanto para as aulas teóricas $(n=17)$, quanto as práticas $(n=19)$ e as gerais $(n=35)$. Uma fala de um aluno serve para ilustrar porque esta sub-categoria foi tão mencionada como influente para que o interesse pela aula seja despertado: ... quando o professor sabe conduzir a aula, relacionando com a realidade, com a prática, explicando tudo o que tem que ser feito, etapa por etapa e tirando dúvidas de todos".

Tabela 3. Freqüência das categorias e sub-categorias apontadas pelos alunos e pelos professores sobre os motivos que levam os estudantes a se interessar ou não pelas aulas teóricas (T), práticas (P) e pelas aulas de um modo geral (G).

\begin{tabular}{|c|c|c|c|c|c|c|c|c|c|}
\hline \multirow{2}{*}{ Categorias } & \multirow{2}{*}{ Sub-categorias } & \multicolumn{4}{|c|}{ Alunos de $1^{\mathrm{a}}$ a $4^{\mathrm{a}}$ séries } & \multicolumn{4}{|c|}{ Alunos de $1^{\text {a a }} 4^{\mathrm{a}}$ séries } \\
\hline & & $\mathrm{T}$ & $P$ & G & Total & $\mathrm{T}$ & $P$ & G & Total \\
\hline \multirow[t]{3}{*}{ A) Estrutural } & Disciplina & 1 & 1 & 9 & \multirow{3}{*}{27} & 1 & 0 & 1 & \multirow{3}{*}{11} \\
\hline & Modulação & 1 & 6 & 0 & & 0 & 1 & 3 & \\
\hline & Materiais & 4 & 3 & 2 & & 1 & 0 & 4 & \\
\hline \multirow{2}{*}{ B) Interacional } & Relação professor-aluno & 2 & 7 & 12 & \multirow{2}{*}{21} & 1 & 2 & 1 & \multirow{2}{*}{5} \\
\hline & Relação aluno-aluno & 0 & 0 & 0 & & 0 & 1 & 0 & \\
\hline \multirow[t]{4}{*}{ C) Pedagógica } & Conteúdos & 4 & 2 & 23 & \multirow{4}{*}{125} & 1 & 3 & 9 & \multirow{4}{*}{40} \\
\hline & Procedimentos de aula & 17 & 19 & 35 & & 3 & 7 & 9 & \\
\hline & Trabalho docente & 5 & 2 & 18 & & 1 & 1 & 4 & \\
\hline & Avaliação do desempenho acadêmico & 0 & 0 & 0 & & 0 & 0 & 2 & \\
\hline \multirow[t]{3}{*}{ D) Comportamental } & Grupal & 4 & 3 & 5 & \multirow{3}{*}{49} & 1 & 0 & 1 & \multirow{3}{*}{20} \\
\hline & Individual do professor & 5 & 2 & 20 & & 2 & 1 & 5 & \\
\hline & Individual do aluno & 0 & 0 & 10 & & 1 & 2 & 7 & \\
\hline \multirow[t]{2}{*}{ E) Comprometimento } & Desempenho acadêmico & 0 & 1 & 7 & \multirow{2}{*}{10} & 2 & 1 & 7 & \multirow{2}{*}{12} \\
\hline & Formação profissional do aluno & 0 & 0 & 2 & & 0 & 0 & 2 & \\
\hline Total & & 43 & 46 & 143 & 232 & 14 & 19 & 55 & 88 \\
\hline
\end{tabular}


Ao observar-se, na Tabela 3, os dados referentes às respostas dos docentes sobre os motivos que levam os alunos a se interessar pelas aulas, vê-se novamente uma concordância de respostas entre os dois grupos de participantes, visto que a sub-categoria Procedimentos de Aula também foi a mais apontada, seja para a as aulas teóricas (3), as práticas (7) ou as gerais (9).

Apesar de mais esta similaridade entre as respostas dadas pelos discentes e docentes, aparece, neste momento, uma grande divergência entre os dois grupos de informantes: enquanto o primeiro parece dar ênfase ao papel desenhado pelo professor para que o aluno se interesse pelas aulas, o segundo, ou seja, o grupo de professores, destaca a categoria Comprometimento, especialmente o Desempenho Acadêmico. Isto aparece claramente quando se observa, na Tabela 3, que a segunda sub-categoria mais apontada pelos alunos foi: nas aulas teóricas, a sub-categoria Comportamento do Professor $(n=5)$; nas aulas práticas, a sub-categoria Relação Professor-Aluno ( $n=7)$; e nas aulas gerais, a subcategoria Comportamento do Professor $(n=20)$. Em contraposição, percebe-se que, segundo a ótica dos docentes, o que influi para que os alunos se interessem pelas aulas relaciona-se à sub-categoria Desempenho Acadêmico $(n=10)$.

É até interessante contrastar o quanto os professores parecem acreditar que a preocupação com o desempenho acadêmico seja algo tão influente no interesse do aluno pela aula, quando os próprios discentes pouco mencionam a categoria Comprometimento $(n=10)$, fazendo dela a categoria menos citada.

Aqui, faz-se possível refletir que, quando os professores apontam que o que leva os estudantes a se interessarem pelas aulas são aspectos desvinculados a eles - como a preocupação do aluno com a nota ou, ainda, o interesse pessoal do estudante pelo conteúdo ministrado -, estão comunicando a sua concepção de que o interesse dos alunos é algo que parte espontaneamente deles, e não, que se trata de algo construído na relação estabelecida entre docentes e discentes. Isto dá margem para que os professores acreditem equivocadamente que, quando um aluno não demonstra interesse por sua matéria, isto se deve ao fato de ele simplesmente não gostar daquele conteúdo, não havendo nada que o professor possa fazer para
despertar-Ihe a atenção, o que vai contra uma das funções primordiais do professor, segundo Monteiro (2002): a de procurar estimular o aluno a interessar-se pelo conteúdo por ele ministrado.

\section{Motivos que levam os alunos a participar ou não nas aulas}

Ao serem indagados sobre os motivos pelos quais os alunos participam em sala de aula, obtiveram-se respostas similares àquelas fornecidas à pergunta sobre os motivos de os alunos se interessarem ou não pelas aulas.

De acordo com a Tabela 4, constata-se que, segundo os alunos, o que os motiva a participar ou não das aulas relaciona-se primeiramente com a categoria Pedagógica ( $n=102$ ) e, em um segundo momento, com a Comportamental $(n=64)$. Dentro da categoria Pedagógica, destacaram-se, pela somatória das respostas nas aulas teóricas, práticas e gerais, as sub-categorias Procedimentos de Aula ( $n=65)$ e Conteúdo ( $n=28)$, tal como ocorreu quando questionados sobre o interesse em sala de aula. Já na categoria Comportamental, as sub-categorias que obtiveram uma maior concentração de respostas, em termos gerais, foram Comportamento Individual do Aluno $(n=29)$ e Comportamento do Professor $(n=27)$.

Como a quinta sub-categoria mais citada, em termos gerais, foi a Relação Professor-Aluno $(n=20)$, pode-se supor que, novamente, os alunos deram ênfase ao papel desempenhado pelo professor, em termos interacionais e comportamentais, como fator influente em sua participação em sala de aula.

Analogamente, também a partir da análise da Tabela 4, vê-se que, para os docentes, as categorias Pedagógica, Comportamental e Comprometimento exercem influência na participação dos alunos. Em especial, foram mais apontadas as sub-categorias Procedimentos de Aula ( $n=15)$, Desempenho Acadêmico ( $n=12)$ e Comportamentos Individuais do Aluno ( $n=10)$. Novamente, tal como ocorreu na questão sobre o interesse do aluno em sala de aula, os docentes parecem não se perceber envolvidos no processo de participação dos alunos em aula, atribuindo como principais motivos para a participação ou não o próprio comportamento do aluno, a despeito de a categoria 
Tabela 4. Freqüência das categorias e sub-categorias apontadas pelos alunos e pelos professores sobre os motivos que os levam os estudantes a participar ou não das aulas teóricas (T), práticas (P) e das aulas de um modo geral (G).

\begin{tabular}{|c|c|c|c|c|c|c|c|c|c|}
\hline \multirow{2}{*}{ Categorias } & \multirow{2}{*}{ Sub-categorias } & \multicolumn{4}{|c|}{ Alunos de $1^{\mathrm{a}}$ a $4^{\mathrm{a}}$ séries } & \multicolumn{4}{|c|}{ Alunos de $1^{a}$ a $4^{a}$ séries } \\
\hline & & $\mathrm{T}$ & $P$ & G & Total & $\mathrm{T}$ & $\mathrm{P}$ & G & Total \\
\hline \multirow[t]{3}{*}{ A) Estrutural } & Disciplina & 0 & 0 & 8 & \multirow{3}{*}{26} & 0 & 0 & 0 & \multirow{3}{*}{6} \\
\hline & Modulação & 2 & 13 & 3 & & 2 & 1 & 2 & \\
\hline & Materiais & & & & & 0 & 0 & 1 & \\
\hline \multirow[t]{2}{*}{ B) Interacional } & Relação professor-aluno & 3 & 4 & 13 & \multirow[b]{2}{*}{27} & 0 & 0 & 3 & \multirow[b]{2}{*}{5} \\
\hline & Relação aluno-aluno & 2 & 2 & 3 & & 0 & 0 & 2 & \\
\hline \multirow[t]{4}{*}{ C) Pedagógica } & Conteúdos & 2 & 0 & 26 & \multirow{4}{*}{102} & 0 & 0 & 1 & \multirow{4}{*}{22} \\
\hline & Procedimentos de aula & 6 & 18 & 41 & & 1 & 8 & 6 & \\
\hline & Trabalho docente & 0 & 1 & 8 & & 0 & 0 & 5 & \\
\hline & Avaliação do desempenho acadêmico & 0 & 0 & 0 & & 0 & 0 & 1 & \\
\hline \multirow[t]{3}{*}{ D) Comportamental } & Grupal & 1 & 1 & 6 & \multirow{3}{*}{64} & 0 & 0 & 1 & \multirow{3}{*}{15} \\
\hline & Individual do professor & 1 & 3 & 23 & & 0 & 0 & 4 & \\
\hline & Individual do aluno & 4 & 2 & 23 & & 2 & 2 & 6 & \\
\hline \multirow[t]{2}{*}{ E) Comprometimento } & Desempenho acadêmico & 2 & 2 & 12 & \multirow{2}{*}{16} & 1 & 3 & 8 & \multirow{2}{*}{14} \\
\hline & Formação profissional do aluno & 0 & 0 & 0 & & 0 & 0 & 2 & \\
\hline Total & & 23 & 46 & 166 & 235 & 6 & 14 & 42 & 62 \\
\hline
\end{tabular}

Comprometimento ter sido, novamente, a menos citada pelos discentes $(n=16)$.

O fato de as respostas sobre as motivações dos alunos em participar ter sido similar àquelas encontradas sobre as suas motivações em interessar-se, do ponto de vista dos dois grupos de participantes, não é de se estranhar. Sabe-se que, apesar de haver uma diferença comportamental entre um aluno que se interessa, mas que não participa, e outro que se interessa e participa, em ambos os casos há um envolvimento de cunho positivo em relação à aula. Interessar-se pela aula e dela participar são fenômenos que, de fato, encontram-se entrelaçados.

\section{Considerações Finais}

A partir da realização deste estudo, observou-se que, tanto para os discentes quanto para os docentes, a relação professor-aluno encontra-se dissociada da relação dos alunos entre si, a despeito de a literatura específica apontar que a maneira como os alunos se relacionam influencia o relacionamento do professor com eles, assim como a interação estabelecida entre o professor e um determinado aluno interfere na maneira como este irá se relacionar com o restante da classe. Pode-se inferir que, talvez, os docentes e discentes façam esta separação por não enxergarem o professor como fazendo parte da dinâmica grupal instaurada em sala de aula. Para eles, o grupo seria constituído pelos alunos, sendo o professor uma figura "de fora".

É possível que esta dificuldade em ver o professor como parte do grupo de alunos esteja relacionada à quantidade de alunos em sala de aula, uma vez que os estudantes falaram mais da relação professor-aluno no contexto de aulas práticas, em comparação às aulas teóricas. Talvez, em uma classe com uma quantidade menor de alunos, a figura do professor faça-se mais presente, ao contrário do que ocorre nas aulas teóricas, nas quais, havendo um grande número de alunos, a sua presença fica mais diluída, tendo que concorrer com uma gama maior de variáveis.

Pode-se, ainda, fazer um paralelo entre o fato de a presença do professor ser ocultada em classes maiores, com a questão do ensino-aprendizagem. Se a influência do docente torna-se minimizada em meio a uma classe com muitos alunos, não ficaria o processo ensino-aprendizagem igualmente prejudicado? Isto se torna preocupante na medida em que, atualmente, observam-se salas de aula contando com um número cada vez maior de alunos. É claro que não se pretende afirmar, neste estudo, que toda aula prática é melhor que qualquer aula teórica, mas é preciso refletir sobre o fato de tanto os docentes quanto os discentes terem demonstrado tanta predileção pelas aulas práticas. 
É possível compreender esta preferência não apenas pelo fato de as aulas práticas contarem com menos alunos em sala de aula, mas, também, por serem diferenciados os procedimentos adotados nestas, em relação às aulas teóricas. Assim, enquanto as primeiras contariam com uma metodologia de ensino mais prática e interativa, as segundas já se caracterizariam pela metodologia tradicional, na qual o professor transmite um corpo de conhecimentos aos alunos.

De fato, a sub-categoria Procedimento de Aula foi amplamente apontada, pelos participantes, como sendo o principal fator para os alunos se interessarem e participarem das aulas. Entretanto, observou-se uma divergência entre o que os professores e alunos consideravam ser um "bom" procedimento de aula. Enquanto, para os primeiros, um bom procedimento de aula consistia no preparo do professor e em sua capacidade de explicar o conteúdo didaticamente, para os alunos, um procedimento de aula bom era aquele no qual o professor passava a matéria dando exemplos práticos, usando falas dos alunos, dentre outras estratégias.

Assim, pode-se fazer a leitura de que, para o grupo de professores, o que faz com que os alunos se interessem pelas aulas são questões relacionadas à técnica pedagógica, enquanto, para os próprios alunos, não seria tanto a técnica, mas a postura atenciosa do professor em contextualizar a matéria com a vida dos estudantes, buscando motivá-los a aprenderem.

Este falta de atenção dos professores à questão da interação estabelecida entre eles e seus alunos como parte importante do processo ensino-aprendizagem foi igualmente notada quando eles, os professores, apontaram como segundo aspecto mais importante para a participação dos alunos nas aulas a preocupação com o desempenho acadêmico - quando, na verdade, os próprios estudantes apontaram a relação professor-aluno e a postura de comprometimento do docente.

Vê-se, desse modo, que os docentes, de maneira geral, não reconhecem a sua verdadeira função no pro- cesso ensino-aprendizagem, acreditando ser profissionais que, por meio de técnicas, devem transmitir um determinado conteúdo. Ainda não assimilaram, a despeito dos diversos estudos que apontam a importância das relações interpessoais no processo de ensino-aprendizagem, o quanto seus papéis de educadores ultrapassam o mero tecnicismo.

\section{Referências}

Bariani, I. C. D. (1992). Significados associados a professor e a aluno, "reais" e "ideais", por estudantes e professores de um curso superior de psicologia. Dissertação de mestrado não-publicada, Universidade Estadual de Campinas.

Coll, C., \& Colomina, R. (1996). Interação entre alunos e Aprendizagem Escolar. In C. Coll, J. Palacios \& A. Marchesi (Orgs.), Desenvolvimento psicológicoeeducação:psicologia da educação. Porto Alegre: Artes Médicas.

Ministério da Saúde, Brasil. (1996). Resolução n. 196/96 sobre pesquisa envolvendo seres humanos. Brasília: Conselho Nacional de Saúde.

Kienen, N., \& Botomé, S. P. (2003). As relações entre controle sobre trabalho e condições de saúde de alunos universitários. Interação em Psicologia, 7 (2), 11-22.

Monteiro, E. A. (2002). A transferência e a ação educativa. Estilos da Clínica, 7 (13), 12-17.

Moraes, M. R. M., \& Bernardino, L. M. F. (2004). Psicanálise e educação: pensando a relação professor-aluno a partir do conceito de transferência. Encontro: Revista de Psicologia, 9 (10), 68-80

Oliveira, E. T. A., \& Wechsler, S. M. (2002). Variáveis que afetam a aprendizagem: percepção de alunos de licenciatura e professores. Psicologia Escolar e Educacional, 2 (6), 133-139

Silva, S. C., \& Aranha, M. S. F. (2005). Interação entre professora e alunos em sala de aula com proposta pedagógica de educação inclusiva. Revista Brasileira de Educação Especial, 11 (3), 373-394.

Zuin, A. A. S. (2003). Sobre a atualidade dos tabus com relação aos professores. Educação Social, 24 (83), 417-427.

Recebido em: 27/7/2006

Versão final reapresentada em: 25/1/2007

Aprovado em: 7/2/2007 
